\title{
Perú al pie del orbe. Homenaje a César Vallejo POR LOS 80 AÑOS DE SU MUERTE
}

\author{
Peru at the foot of the orb. Tribute to César Vallejo for 80 years of his death
}

Manuel Pantigoso Pecero ${ }^{(1)}$

\section{RESUMEN}

El ensayo destaca la poca receptividad de la obra vallejiana por parte de la crítica de su tiempo. Asimismo, recoge las palabras laudatorias de González Prada, Eguren, Valdelomar, Orrego, Mariátegui y Basadre. Luego de la polémica con los escritores de vanguardia, se insertan dos momentos generacionales: la del 27 española, y la del 30-36 en el Perú. Finaliza con los homenajes de Neruda y Georgette de Vallejo al poeta inmortal.

Palabras claves: Incomprensión, homenaje, autenticidad, vanguardia, generaciones.

\section{INTRODUCCIÓN}

D esde que se cumplió su presagio de "Piedra negra sobre piedra blanca": "me moriré en París con aguacero...", la poesía de César Vallejo se reactualiza en el lenguaje de los nuevos poetas. Hace varias décadas venimos estudiando su obra y su vida; el año 2000 publicamos diversos trabajos sobre la poética vallejiana con el título de Se llama Lomismo que padece (Eccehomo). Ahí aparece la propuesta de una nueva estética de vanguardia referida al "homo", es decir al hombre, que hemos denominado Lomismo. En este homenaje por los 80 años de su fallecimiento ofrecemos una rápida panorámica sobre personajes, escritores y amigos del vate santiaguino que en las circunstancias más oscuras de su vida se refirieron a su obra de manera elogiosa.

1 Poeta, crítico literario y de arte, autor teatral, periodista y maestro universitario. Miembro de Número de la Academia Peruana de la Lengua.

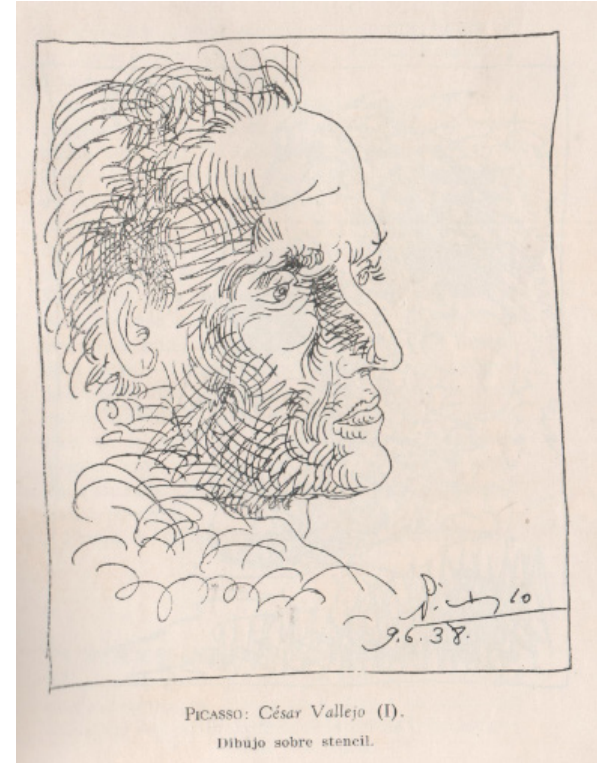

Fuente: https:/ / copypasteilustrado.wordpress.com

\section{EL POETA “SIN POEMAS" SE ENCUMBRA DESDE EL DOLOR}

Vallejo es uno de los más grandes poetas de nuestro idioma; sin embargo antes de su muerte su obra poética fue incomprendida y silenciada. Salvo el esfuerzo de sus amigos y la lucidez de muy pocos escritores, la crítica no entendió entonces el mensaje trascendente de una poética que problematizaba el ser del hombre, y que luego de Los Heraldos Negros, con Trilce, radicaliza su lenguaje contraponiendo "intensidad y altura". Fue un libro de avanzada que rompió los esquemas del Modernismo circundante. 
Mucho se especula sobre el conocimiento que Vallejo tuvo de las escuelas de Vanguardia. Se hace alusión al Dadaísmo que traía vocablos inconexos, sin sentido, y con grafías inexplicables. En el caso denuestro santiaguino, hay un hecho que pocos han tomado en cuenta: el vínculo espiritual entre el poeta y un periodista y escritor extraordinario y muy amigo suyo: Adán Felipe Mejía apodado "El Corregidor", gran conocedor del lenguaje y adicto al juego verbal. Hay algo en tal sentido que los une: el espíritu vanguardista en la recomposición de las palabras para crear otras de significación intensa.

Según menciona Américo Ferrari, Vallejo solía escoger una palabra, repetirla monótona, infatigablemente, hasta vaciarla de su sentido normal o convencional, hasta destruir con esta repetición absurda toda su sustancia lógica, hasta hacer de la palabra exactamente lo que toda palabra es en su esencia: un problema. Su viuda, Georgette Philippart, comentó en relación a esto lo siguiente: "Yo le oí, pero en sentido contrario, repetir una palabra como si quisiera saturarse de ella, dilatándola, hasta hacer alcanzar a la palabra una dimensión monstruosa que revelaba un contenido fenomenal y hacía pensar en la desintegración del átomo"(1). Estos dos juegos opuestos revelarían, en todo caso, el flujo y reflujo de la obra de Vallejo a la que al inicio, la mayoría consideraba como algo que no se podía interpretar como poesía.

Chocano se burló del "poeta sin poemas", y hasta Alberto Ureta "se mofaba del loco provinciano que escribía extravagancias, con la deliberada intención de no ser entendido" (Coyné, 1989:89). El propio Luis Alberto

1 Internet: (https: / / elpais.com/diario/1988/04/15/cultura/577 058407_850215.html)
Sánchez declarábase sorprendido y escribió lo siguiente: "César Vallejo ha lanzado un nuevo libro incomprensible y estrambótico: Trilce". Y tornaba a preguntarse: "Pero ¿Por qué habrá escrito Trilce Vallejo?" (Rivero-Ayllón 2004:85).

\section{ELOGIO DE RECONOCIDOS ESCRITORES PERUANOS}

Sigamos la ruta de aquellos escritores que comprendieron su poesía. Los poetas suelen entender a los poetas. Uno de ellos, de gran influencia en el Perú, Manuel González Prada, tenía en estima los versos de Vallejo. Sería el propio vate santiaguino quien al dedicarle el poema "Los dados eternos" le escribió lo siguiente: "Para Manuel González Prada, esta emoción bravía y selecta, una de las que, con más entusiasmo, me ha aplaudido el gran maestro". El 9 de marzo de 1918, en el diario "La Reforma" de Trujillo, aparece la entrevista que Vallejo le hace en las instalaciones de la Biblioteca Nacional. Durante la conversación hay un momento iluminado. Las palabras de González Prada calarían hondo en la conciencia de Vallejo que las tendría muy presentes al momento de escribir esa obra maestra, como es Trilce. Leamos:

-Sí, pues -me contesta-, hay que ir contra la traba, contra lo académico.

Chispea en sus ojos videntes un diamante prócer. Y me acuerdo de aquella biblia de acero que se llama Pájinas libres. Y creo envolverme en el incienso de un moderno retablo sin efigies.

-En literatura -prosigue- los defectos de técnica, las incongruencias en la manera, no tienen importancia.

-Y las incorrecciones gramaticales -le pregunto-, evidentemente. ¿Y las audacias de expresión? 
Sonríe de mi ingenuidad; y labrando un ademán de tolerancia patriarcal, me responde:

-Esas incorrecciones se pasan por alto. Y las audacias precisamente me gustan. Yo bajo la frente.

Igualmente, el joven Vallejo recibiría una carta laudatoria del poeta simbolista José María Eguren quien, con breves palabras acertaría en señalar lo más característico de su obra: "Sus versos me han parecido admirables por la riqueza musical e imaginativa y por la profundidad dolorosa". Fechada el 15 de julio de 1917, esta misiva sería publicada en "La Reforma", el 21 de julio de 1917. Tal vez sea Eguren el primero que supo referirse a esa armonía vallejiana como revelación del uno mismo, del adentro, como luego lo demostraría esclarecidamente Xavier Abril en su libro Exégesis Trílcica, publicado en 1980. Para formular la teoría sobre la musicalidad en Vallejo, el poeta y crítico recoge esas palabras iluminadoras de Eguren.

Por su parte, Abraham Valdelomar, en 1918 (en la revista "Sudamérica"), llama a Vallejo "Poeta de la ternura", "hermano en el dolor y en la belleza, hermano en Dios", en cuyo espíritu arde "la chispa divina de los elegidos". El 18 de enero de 1918, en el diario "La Reforma" de Trujillo, se publicaría la entrevista que hiciera Vallejo al "Conde de Lemos". Fue una amistad breve. Había entre Valdelomar y Vallejo cierta afinidad que se manifestaba en la honda identificación con el hogar, los padres, los hermanos, y el diálogo con Dios. El narrador iqueño no alcanzaría a escribir el prólogo de Los Heraldos Negros, conforme al ofrecimiento que le hizo a Vallejo. La muerte se lo impidió. Sin embargo, antes que tañera el adiós final, el "Conde de Lemos" alcanzó a escribir un poema a su joven amigo que resultó a la postre un texto casi desconocido (Naranjo, 2011:111):

Vamos al campo. César. Pon tu mano en mi brazo.

Deja tu nido roto, ven al campo conmigo. Para tu hondo dolor, mi corazón amigo será como un piadoso y tranquilo regazo. Iremos conversando, bajo la paz del cielo, sobre las mustias hojas, en la tarde serena. Mientras se ponga el sol tú me dirás tu pena y el viento cantará canciones de consuelo. Un ave cruzará por el cielo encendido, los sauces llorarán, preludiarán los grillos su taciturno canto, el ángelus será una mística cita

y bajo un árbol viejo, de metálicas hojas, ante nuestras pupilas veladas por el llanto en la triste avenida de metálicas hojas se esfumará la blanca sombra de Margarita.

Hay expresiones de Valdelomar muy próximas a Los Heraldos Negros: "nido roto", "hondo dolor", "piadoso y tranquilo regazo", "me dirás tu pena", "los sauces llorarán", "taciturno canto", "mística cita", "metálicas hojas", "pupilas veladas por el llanto", "blanca sombra".

Otro momento destacable son las palabras prologales de Antenor Orrego a Trilce, texto medular que revela el legado prístino del verbo vallejiano. Ese año, Chocano sería coronado a la usanza romana imperial. El libro caería en el vacío, con un lenguaje que celebraba la orfandad de la existencia. Lo dice el propio poeta en una carta dirigida a Antenor Orrego: "Me siento colmado de ridículo, sumergido a fondo en ese carcajeo burlesco de la estupidez circundante, como un niño que se llevara torpemente la cuchara por las narices" (Vallejo 2002:46). 
El prólogo de Orrego sería el primer estudio profundo de la poesía vallejiana (Vallejo 1991:208-209):

La América Latina -creo yo- no asistió jamás a un caso de tal virginidad poética. Es preciso ascender hasta Walt Whitman para sugerir, por comparación de actitudes vitales, la puerilidad genial del poeta peruano. (...) Sus palabras no han sido dichas; acaban de nacer. El poeta rompe a hablar porque acaba de descubrir el verbo.

Contra lo que dice André Coyné, que Orrego usa en su introspección estética "un vocabulario y una problemática trasnochada" (1989:88), nosotros, por el contrario, consideramos que ese prólogo es una obra maestra que permite al lector entender la polivalencia del verbo trílcico. Con notable acierto -y siguiendo lo dicho por Eguren- Orrego destaca el elemento musical en los poemas de Vallejo (Vallejo 1991:211):

He aquí la más grande función del artista: descubrir el ritmo y, por medio de su arte, expresarlo. El artista no es sino un simple vehículo o conductor. Este es el único sentido de la palabra creación. Los ritmos de las cosas están esperando, desde toda eternidad, un revelador. Darío dijo, si mal no recuerdo, que cada cosa está aguardando su instante de infinito. Este instante no es sino aquel en que el artista descubre el ritmo de cada cosa o de cada ser, que al mismo tiempo que lo relaciona con el Universo también lo determina.

Por nuestra parte, podríamos reconocer dos tendencias musicales en América: una que continúa el rastro de Verlaine (tan reclamada por Darío), y la otra que sigue a Mallarmé, más próxima a Vallejo. Así mismo, hemos señalado que lo consubstancial del vate de Santiago de Chuco se da a partir de la llamada
"Estética de la experiencia" o de la poética del "estruendomudo" (expresión que está en uno de sus poemas), en donde la sexualidad y la sensibilidad se unen para expresar los hondos contenidos emocionales.

A su vez, José Carlos Mariátegui, en su clásico 7 ensayos deinterpretación dela realidad peruana, cataloga a Vallejo como "el poeta de una estirpe, de una raza. Se encuentran en Vallejo, por primera vez en nuestra literatura, el sentimiento indígena virginalmente expresado" (p. 268). Mariátegui asume esa "caída" de la escritura trílcica como prueba del auténtico poema que se despoja de todo ornamento retórico y ofrece, desnudo, su acento inconfundible (p. 275):

Vallejo, en su poesía, es siempre un alma ávida de infinito, sedienta de verdad. La creación en él es, al mismo tiempo, inefablemente dolorosa y exultante. Este artista no aspira sino a expresarse pura e inocentemente. Se despoja, por eso, de todo ornamento retórico, se desviste de toda vanidad literaria. Llega a la más austera, a la más humilde, a la más orgullosa sencillez en la forma.

Vallejo le agradecería al "Amauta" con las siguientes palabras (Cuadernos 1988:19):

Mi querido compañero:

Agradezco a usted en lo que vale el bondadoso juicio que me envía, publicado en "Mundial" relativo a mi labor literaria. Varios pasajes de su cariñoso ensayo llevan la voluntad de comprensión y logran interpretarse con tan penetrativa agilidad, que leyéndolos me he sentido como descubierto por la primera vez y como revelado en modo concluyente. Su ensayo, sobre todo, está lleno de buena voluntad y de talento. Le agradezco, querido compañero, por ambas cosas. 
Ese mismo año, en 1928, Jorge Basadre iniciaba un paralelo entre "los dos poetas más difíciles del Perú: Eguren y Vallejo". Se trataba de un momento crucial de definición de la poesía contemporánea frente al modernismo. Ambos poetas traían al público otros paradigmas y exigencias que no lograba entender el mensaje que. Era un lenguaje que presentaba una idea, un sentimiento, una intuición. Frente al enjoyamiento de la imagen descriptiva, Eguren y Vallejo oponían el elemento simbolista, abstracto, impreciso, polivalente. Había fuerza, novedad, intriga y desafío en la palabra. Diría Basadre (Amauta 21:28-29):

César Vallejo es, cronológicamente, nuestro segundo "poeta difícil". Con lo que viene, necesariamente, una comparación entre Vallejo y Eguren. La reacción del público es análoga ante ambos. En el fondo, ambos traen a nuestra literatura, por caminos inhollados, el sentido de lo trágico cotidiano, que por más que se ahonde siempre aparece como inédito.

(...)

La melancolía de Eguren hiere; el dolor de Vallejo desgarra. La una penetra como una niebla; el otro estruja como una zarpa. Eguren no comprende que Vallejo ponga la palabra "cobrador" para sugerir una emoción estética aunque sea líricamente; Vallejo no comprende que Eguren se solace pintando la liga de la marquesita de "Colonial". Vallejo viene de la sierra, del pueblo con un sello de Autoctonismo; Eguren es un producto aristocrático, tan aristocrático que no tiene contacto con nuestra realidad abigarrada. Vallejo es más humano y Eguren más artista. Los poemas de Vallejo dan la sensación de algo no concluido, de algo a medio hacer, pero con un estupendo fracaso; los poemas de Eguren dan la sensación de algo acabado.

\section{ENCONTRONAZO CON LOS POETAS DE VANGUARDIA}

A pesar de que Vallejo traía a la poesía una técnica y un espíritu nuevo, no fue un propulsor de las corrientes de vanguardia. Cuando escribe sobre sus coetáneos declara su rechazo total del aporte de quienes están renovando profundamente la poesía hispanoamericana. Resulta curioso que el poeta más hondamente innovador se fije más en las extravagancias propias de la época que en los genuinos esfuerzos de explorar rumbos nuevos. Leamos el siguiente fragmento (Verani, 1995:192):

La actual generación de América no anda menos extraviada que las anteriores. La actual generación de América es tan retórica y falta de honestidad espiritual, como las anteriores generaciones de la que ella reniega. Levanto mi voz y acuso a mi generación de impotente para crear o realizar un espíritu propio, hecho de verdad, de vida, en fin, de sana y auténtica inspiración humana. Presiento desde hoy un balance desastroso de mi generación, de aquí a unos quince $\mathrm{o}$ veinte años. (...)

Un verso de Neruda, de Borges o de Maples Arce, no se diferencia en nada de uno de Tzara, de Ribemont o de Reverdy. En Chocano, por lo menos, hubo el barato americanismo de los temas y nombres. En los de ahora, ni eso.

Estas declaraciones le significarían encontronazos con los nuevos escritores de vanguardia, entre ellos, Serafín Delmar y Gamaliel Churata, en Perú, y Arturo Uslar Pietri desde Caracas. En verdad, el recusamiento de Vallejo se sustentaba en el hecho de ver el mero juego del ingenio, la novedad formal como fin en sí mismo, pero sin calar en la fuerza vital y 
en la sinceridad expresiva de la nueva poesía. Delmar respondería a Vallejo con las siguientes palabras:

La nueva generación de poetas -respondemos del Perú- es el producto más honrado que se ha dado sobre el desprestigio del afeminamiento limeño, i de la toxicomanía asimilada de los provincianos. I son revolucionarios porque es del dolor proletario de donde arrancan las más profundas raíces de humanidad, i aman la máquina, el vértigo de los rascacielos, el dinamismo cósmico de los motores, porque allí está la FUERZA armada del Cerebro creador ${ }^{(2)}$.

Por su parte el narrador venezolano Arturo Uslar Pietri señalaría lo siguiente (Verani, 1995:173):

Bien se ve que no se ha tomado el trabajo de saber que pertenecemos a una cultura, en todo el ancho sentido que encierra el puñado de letras, y que un fenómeno de ella ha de arropar a todos los hombres que la constituyen con las necesidades de las fuerzas fisiológicas, sin que puedan decirse plagiarios los unos de los otros, pero sí con el derecho de llamar desertores o rezagados a los que no tienen el valor de colocarse en su momento histórico.

\section{VALLEJO Y LA GENERACIÓN PERUANA DEL 30-36}

En la Generación del 30-36 hay un hecho revelador: En 1938 una delegación de escritores del "Grupo Palabra", compuesta por Augusto Tamayo Vargas, Alberto Tauro del Pino, Carlos Cueto Fernandini y José Mejía Baca viajó a

2 "El atraso de César Vallejo", en revista "Guerrilla" No 1, Lima, 1927.
Europa y llegó a París quince días después de la muerte de César Vallejo. Dentro de esta generación Luis Felipe Alarco sería uno de los primeros -si no el primero- en estudiarlo con seriedad en un trabajo leído en una radio de Arequipa, en 1935, titulado "Semblanza de César Vallejo"; por su parte Estuardo Núñez, en Panorama actual de la poesía peruana, fue el primero en calificarlo como representante del expresionismo peruano. Así lo reconoce también Roberto Paoli, quien en el artículo "¿Por qué Vallejo? Un nuevo revolucionario del idioma" estudia al autor de Trilce desde su matriz (Buendía, 1988:222):

Cronológicamente, el primero en hablar de un expresionismo de Vallejo fue el estudioso peruano Estuardo Núñez en su Panorama actual de la Poesía Peruana (...) conocedor de la literatura alemana y lector de los poetas expresionistas, no tuvo dificultad para establecer este paralelo, fundándolo sobre una convergencia de sensibilidades másbienquesobreprecisascorrespondencias estilísticas.

Un ejemplar de ese "panorama" pudo llegar, en los primeros meses de 1938, a las manos de Vallejo ya enfermo y alcanzó a leerlo, según el testimonio de Raúl Porras Barrenechea (1993:139): “A su lecho de enfermo de agonía le llegó algún volumen que venía del Perú y en el que Estuardo Núñez lo reconoció como el más alto valor de la poesía peruana actual".

\section{VALLEJO Y LA GENERACIÓN POÉTICA ESPAÑOLA}

En 1931 Vallejo llega a España con Georgette y pasa una temporada que puede considerarse entre las mejores de su vida. Se relaciona en Madrid con Federico García Lorca, Rafael Alberti, Antonio Machado, Pedro Salinas y Luis Cernuda. 
Cuando fue publicada en Madrid la segunda edición de Trilce, el libro salió con un prólogo del español José Bergamín quien señalaba como elemento primordial las raíces de la lengua (Vallejo s/f:22):

Su arraigo idiomático castellano. (...) En este sentido, el libro Trilce, de César Vallejo, tuvo un logro profético, adelantándose con la ingenua espontaneidad de poesía recién nacida: y adelantándose tanto, que hoy mismo nos sería difícil encontrarle superación entre nosotros; en su autenticidad y en sus consecuencias.

En esa edición madrileña aparece también un notable poema de Gerardo Diego, titulado "Valle Vallejo" que se vincula con la técnica del poeta peruano por la aparente incoherencia de los nexos imaginativos. Ese libro vendría a ser el homenaje ofrecido por los poetas de la Generación del 27. Leamos (Vallejo s/f:27):

Alberto Samain diría Vallejo dice Gerardo Diego enmudecido dirá mañana y por una sola vez Piedra de estupor y madera dulce de establo querido amigo hermano en la persecución gemela de los sombreros desprendidos por la velocidad de los astros.

Piedra de estupor y madera noble de establo constituyen tu temeraria materia prima anterior a los decretos del péndulo y a la creación secular de las golondrinas.

Naciste en un cementerio de palabras una noche en que los esqueletos de todos los verbos intransitivos proclamaban la huelga del te quiero para siempre siempre siempre una noche en que la luna lloraba y reía y lloraba y volvía a reír y a llorar jugándose a sí misma a cara o cruz.
Y salió cara y tú viviste entre nosotros

Desde aquella noche muchas palabras apenas

nacidas fallecieron repentinamente tales como Caricia Quizás Categoría Cuñado Cataclismo

Y otras nunca jamás oídas se alumbraron sobre la tierra así como Madre Miga Moribundo Melquisedec Milagro y todas las terminadas en un rabo inocente. Vallejo tú vives rodeado de pájaros a gatas en un mundo que está muerto requetemuerto y podrido.

Vives con tus palabras muertas y vivas Y gracias a que tú vives nosotros desahuciados acertamos a levantar los párpados para ver el mundo tu mundo con la mula y

el hombre guillermosecundario y la tiernísima niña y los cuchillos que duelen en el paladar.

Porque el mundo existe y tú existes y nosotros probablemente terminaremos por existir si tú te empeñas y cantas y voceas en tu valiente valle Vallejo.

Otro poeta notable de dicha generación, Jorge Guillén, escribe, con su peculiar acento, un texto-homenaje bastante concentrado que refleja trazos de la poética vallejiana a partir de palabras clave como: "arranque profundo", "balbuceo", "borrador de las entrañas", "pujando hacia la luz", "cárdena violencia”, "gemido encanto" (Forgues 1994:139):

Al margen de César Vallejo Mineral, Animal, Espíritu. 
Oscuro arranque profundo

Se transmuta en balbuceo

De un hombre que es una roca,

Trozo aún de serranía.

¿Borrador de las entrañas?

No. Pujando hacia la luz

de cárdena violencia

Concluye el gemido en canto:

De la desesperación

Va surgiendo la esperanza.

En esta etapa referida a poetas de la Generación del 27 no podemos dejar de hablar de Juan Larrea, uno de los grandes amigos de Vallejo. Su obra poética fue publicada con el título de Versión celeste. Es cierto que varios estudiosos de su obra, como Vittorio Bodini, la relacionan con el Surrealismo, pero el propio Larrea dijo que la etiqueta que mejor le cuadraba era la de Ultraísta, pues su trayectoria fue un intento constante de ir ultra (más allá) del entorno vital y social que le oprimía. Larrea empieza a escribir en pleno auge de la Vanguardia y sus primeros poemas se publican en revistas ultraístas como "Grecia" y "Cervantes". Tuvo fascinación por el Creacionismo de Huidobro, que dura hasta 1926, fecha en la que en París edita con César Vallejo, "Favorables-ParísPoema", revista vanguardista de vida efímera y periodicidad trimestral; solo se editaron dos números fechados en julio y octubre de 1926. Además de artículos literarios firmados por los ya citados, incluye poemas de Gerardo Diego, Tristán Tzara, Vicente Huidobro, Pablo Neruda, Juan Gris y Pierre Reverdy. Al final del segundo número aparece un listado de las colaboraciones rechazadas, pertenecientes, entre otros, a Azorín, Gabriela Mistral y Ramón Pérez de Ayala. De 20 páginas cada número, fue estampada en la Imprenta Española Aurora de la capital francesa.

El español Juan Larrea contó siempre con la admiración y amistad de Gerardo Diego, quien lo incluyó en sus famosas antologías. Su pasión por la poesía de Vallejo es irrefutable. Vallejo murió en 1938, Larrea en 1980. Su devoción por el peruano se puede apreciar en la reedición de sus libros, en sus monografías, en la organización de congresos para recordar al amigo. Y publicó libros como César Vallejo o Hispanoamérica en la Cruz de su Razón (1958), Teleología de la cultura (1965), Del surrealismo a Machu Picchu (1967), trabajos consagrados a pensar y repensar la obra vallejiana.

En el caso de "Aula Vallejo", que apareció de 1961 a 1974 en Córdoba, Argentina y sirvió para cuajar la admiración sentida por Larrea hacia la figura del peruano, se editaron cinco ejemplares, todos ellos con extraordinarias colaboraciones, en donde es visible el prestigio casi mitológico del que ya gozaba por aquellos años la figura del poeta nacido en Santiago de Chuco. La revista tuvo una vida larga (trece años), aunque sus números hayan sido escasos. En ella también se recuerda la amistad entre Vallejo y Larrea, los años parisinos, la vanguardia y la publicación de "FavorablesParís-Poema".

\section{RETRATOS DE VALLEJO POR PICASSO}

Picasso y Vallejo no se conocieron, pese a que ambos vivieron en París y militaron en el Partido Comunista Francés en los años 30. La creencia de que fueron amigos proviene de los retratos del poeta que el artista dibujó. Pero eso ocurrió el 9 de junio de 1938, casi dos meses después de la muerte de Vallejo ocurrida el 15 de abril, luego de que Juan Larrea le leyera al pintor unos poemas del peruano. Le impactaron de tal manera que respondió "A este sí le hago yo un retrato", según cuenta Larrea, y lo hizo sobre la fotografía de la mascarilla mortuoria del vate. 
La otra fuente de la confusión proviene de un artículo de 1927 en que Vallejo narra su encuentro con Picasso a la salida de una galería, cuando el escultor español Decrefft los presentó. Pero fue un encuentro al paso. Para esos años Picasso, casado con la bailarina rusa Olga Khokhlova, había alcanzado fama y fortuna y ya no frecuentaba a sus amigos bohemios, incluidos los españoles. Pero a Vallejo eso le tiene sin cuidado (Puccinelli, 1987:209): “Quien ha creado una obra tan multánime e imperecedera, está en libertad de vivir, si le place, sentado en la propia nariz de Minerva, haciéndola chillar en ágoras y mercados. El genio tuvo siempre cogida por el rabo a la moral".

Rafael Alberti, otro notable poeta de la Generación del 27, siempre tuvo palabras de elogio para el vate peruano a quien conoció en plena etapa de efervescencia vanguardista. Diría en una entrevista (Naranjo 2011:170):

Yo con Vallejo tuve una amistad muy dispersa. Yo vivía en Madrid y él vivía en París habitualmente, pero las veces que coincidíamos, aquí o en Francia, le veía a menudo. Conmigo siempre fue muy gentil, como solía serlo con la gente. Era muy silencioso, o más bien diría hermético. Era más hermético que otra cosa, quizá era parte de su expresión racial. Solía estar callado y pensativo.

En las siguientes palabras, Alberti no oculta nada su admiración por el autor de Poemas Humanos (Naranjo 2011:171):

Vallejo es uno de los poetas más grandes del idioma. Con Rubén Darío y Pablo Neruda, son los tres poetas cumbres de la lengua latinoamericana. Vallejo sigue teniendo una presencia actual muy importante. Es quizá el más humanista, el más terrenal de los tres que he citado, el más enraizado en la tierra.

La poesía de Vallejo era muy personal. Él llegó a crear un lenguaje poético muy suyo, dándole al idioma una torcedura especial que es propia de su identidad. Yo creo que esta conmemoración de su muerte servirá para reafirmar que Vallejo es un poeta eterno, al que no hace falta discutir.

\section{PABLO NERUDA Y VALLEJO}

Mucho se ha hablado y escrito sobre las diferencias que pudo haber entre estos dos inmensos poetas. Las especulaciones no han cesado, pero lo cierto es que Neruda dedicó varios textos y poemas a Vallejo. En la fecha de su muerte escribiría unas palabras sentidas que muestran su pesar por la desaparición de su amigo:

"Cesar Vallejo ha muerto"

"Rindió tributo a sus muchas hambres" -me escribe Juan Larrea-. Muchas hambres, parece mentira... Las muchas hambres, las muchas soledades, las muchas leguas de viaje, pensando en lo hombres, en la justicia sobre esta tierra, en la cobardía de media humanidad. Lo de España ya te iba royendo el alma. Esa alma tan roída por tu propio espíritu, tan despojada, tan herida por tu propia necesidad ascética. Lo de España ha sido el taladro de cada día para tu inmensa virtud. Eras grande, Vallejo. Eras interior y grande, como un gran palacio de piedra subterránea, con mucho silencio mineral, con mucha esencia de tiempo y de especie. Y allá en el fondo el fuego implacable del espíritu, brasa y ceniza... Salud, gran poeta, salud, hermano. (Revista Aurora de Chile, No. 1, del 1ro. de agosto de 1938) ${ }^{(3)}$

3 Internet: Vallejo Pablo Neruda César Vallejo ha muerto 
Culminemos con la figura de Georgette de Vallejo (París, 1908-Lima, 1984), Después de la muerte de su esposo en 1938, ella conservó abnegadamente todos sus manuscritos salvándolos de una segura desaparición durante los años de la ocupación alemana de París, y luchó durante el resto de su vida por difundir el legado de su esposo. De no ser por su fervorosa dedicación la obra literaria de Vallejo no tendría ahora la difusión mundial que tiene. Llegaría al Perú en 1951 para defender la integridad del legado de su esposo con tal ardor que le granjeó la enemistad de muchos estudiosos y especialistas. Leamos el hermoso poema que le dedicó a su compañero de la vida y de la muerte (Naranjo 2011:188):

Oh dolor

Inmaculada concepción de la muerte.

Ya la muerte te sonreía

por las pupilas de tus lágrimas

escuchando en el caer de la noche apagarse los diarios de la tarde.

Encaramada en tu delirio

la fiebre mide tus orinas de cobre

filtrando impasible tu postrera agonía.

$Y$ es la morada de la última primavera.

En la mesa ataviada de verde seda

has quedado inclinado

refluyendo el dolor

de tanta nueva desdicha.

A tus dedos sacando tierra

pedazos de ese azul ajado

de un viaje

destrozado.

\section{PALABRAS FINALES}

Vallejo es el poeta más original de la vanguardia histórica y el más influyente de nuestro siglo en Latinoamérica. Su obra fue poco conocida mientras vivió, y hasta pocos años después de su muerte no se terminaron de publicar sus escritos. Sin embargo, tuvo el aprecio y el reconocimiento a su poesía por parte de los grandes escritores del Perú. Con el paso del tiempo, su renovador lenguaje y su fuerza poética han ido ganando influencia en la poesía en castellano. A los 80 años de su muerte los estudios sobre su obra se siguen multiplicando y su fértil sombra sigue extendiéndose sobre la literatura contemporánea.

\section{BIBLIOGRAFÍA}

1. BASADRE, Jorge. 1929. “Elogio y elegía de José María Eguren", Amauta 21:21-29. Lima: Empresa Editora Amauta.

2. BUENDÍA Sialer, Bruno. 1988. Caminando con César Vallejo. Actas del Coloquio Internacional sobre César Vallejo. Lima: Editorial Perla.

3. COYNÉ, André. 1989. César Vallejo. Lima: Ediciones Sea.

4. CUADERNOS Hispanoamericanos. 1988. Homenaje a Vallejo. Madrid. Gráficas Lérida.

5. FORGUES, Roland. 1994. César Vallejo vida y obra. Lima: Amaru Editores.

6. NARANJO, Reynaldo. 2011. César Vallejo en el siglo XXI. Lima: Universidad César Vallejo.

7. NÚÑEZ, Estuardo. 1993. Panorama actual de la poesía peruana. Lima: Ediciones Sea (Segunda Edición).

8. PUCCINELLI, Jorge. 1987. César Vallejo desde Europa. Lima: Ediciones Fuente de Cultura Peruana.

9. RIVERO-AYLLÓN, Teodoro. 2004. Vallejo y ese 15 de abril... Trujillo: Trilce Editores.

10. VALLEJO, César. 1991. Obras completas. Lima: Banco de Crédito del Perú.

11. - 2002. Correspondencia Completa. Lima: Pontificia Universidad Católica del Perú.

12. - s/f. Trilce. Lima: Editora Nuevo Perú.

13. VERANI, Hugo. 1995. Las vanguardias literarias en Hispanoamérica. México: Fondo de Cultura Económica (Tercera Edición). 